\title{
Nursing staff requirements for neonatal intensive
} care

\author{
S Williams, A Whelan, A M Weindling, R W I Cooke
}

\begin{abstract}
A study to estimate the number of nursing staff required for neonatal nursing was undertaken. Certain nursing tasks, such as transporting any infant, caring for the dying infant, and looking after the very unstable infant required continuous attention by one nurse $(5.5$ whole time equivalent (wte) nurses for each cot). The stable ventilated infant required 10.5 nursing hours each day - that is, 2.4 wte/cot. Infants with intravenous infusions, but not ventilated, required only slightly less nursing time: $\mathbf{9 \cdot 2 5}$ nursing hours each day or $2 \cdot 12$ wte/cot. Each special care patient needed 6.50 nursing hours each day, or 1.49 wte/cot. It is emphasised that each neonatal unit will have to take its own practices into account when calculating neonatal nursing requirements.

(Arch Dis Child 1993; 68: 534-538)
\end{abstract}

There have been a number of recommendations in the United Kingdom for the number of nurses required to staff a neonatal intensive care unit. Among these have been guidelines issued by the English National Board for Nursing, Midwifery and Health Visiting, ${ }^{1}$ recommending that there should be a minimum of four nurses for every intensive care cot, three for each high dependency cot, and a minimum of 1.25 nurses for every special care cot. In 1988, the Royal College of Physicians of London recommended that the appropriate level for an establishment was five nurses for every intensive care cot and 1.5 nurses for every special care cot. ${ }^{2}$ In 1991 a further circular from the English National Board ${ }^{3}$ no longer gave precise recommendations, but stated that 'the range of staff should provide an appropriate skill mix for the level of special/intensive care required in the unit and should reflect the progressive needs of babies from prenatal to postnatal life and into childhood.' In 1992 a working group of the British Association of Perinatal Medicine and the Neonatal Nurses Association ${ }^{4}$ recommended that maximum intensive care requires 5.5 whole time equivalent (wte) nurses for each cot, high dependency intensive care requires 3.5 wte nurses for each cot, and special care requires 1.0 wte nurses for each cot. That report added the caveat that 'on presentation of appropriate research findings these [recommendations] may require amending.'

To assess workload demands it is of the utmost importance that we know how much time neonatal nurses spend giving direct care to their patients. The most popular methodology available is activity analysis. Once the results of the activity analysis have highlighted what duties nurses perform during their span of duty, a demand profile can be determined for each patient; this has to be based on the amount of care needed and not just on the clinical diagnosis because an individual patient's input need can change from one nursing shift to the next.

To take account of local conditions, the classification of patients' demand groups must be carried out at a local level to ensure maximum benefit to patients and staff. None of the available methods is theoretically perfect but, if used well, can help to improve the consistency of care for patients. This type of approach may also go some way towards reducing the stress of 'peaks' and the frustration of the occasional 'trough' for staff, particularly relevant for a specialty as prone to fluctuations in demand as neonatal intensive care.

This paper describes a study which was undertaken to estimate the amount of nursing staff activity that was required to care for infants with different nursing needs.

\section{Methods}

The study was carried out in the neonatal unit at Liverpool Maternity Hospital. This regional level 3 nursery admits approximately 450 infants a year and around 300 are ventilated.

The first phase of this study examined how nurses who were working on a neonatal unit spent their working hours. The neonatal nurses were also asked to comment on the quality of the care that they felt they were providing on each shift. The second phase of this study examined the nursing requirements of infants admitted to the neonatal unit. A third phase tested the applicability of the formulas that were derived.

PHASE ONE: HOW NURSES SPENT THEIR TIME The nursing activity analysis scheme that was used classified each nursing task as falling into 
Table 1 Neonatal unit nursing staff categories

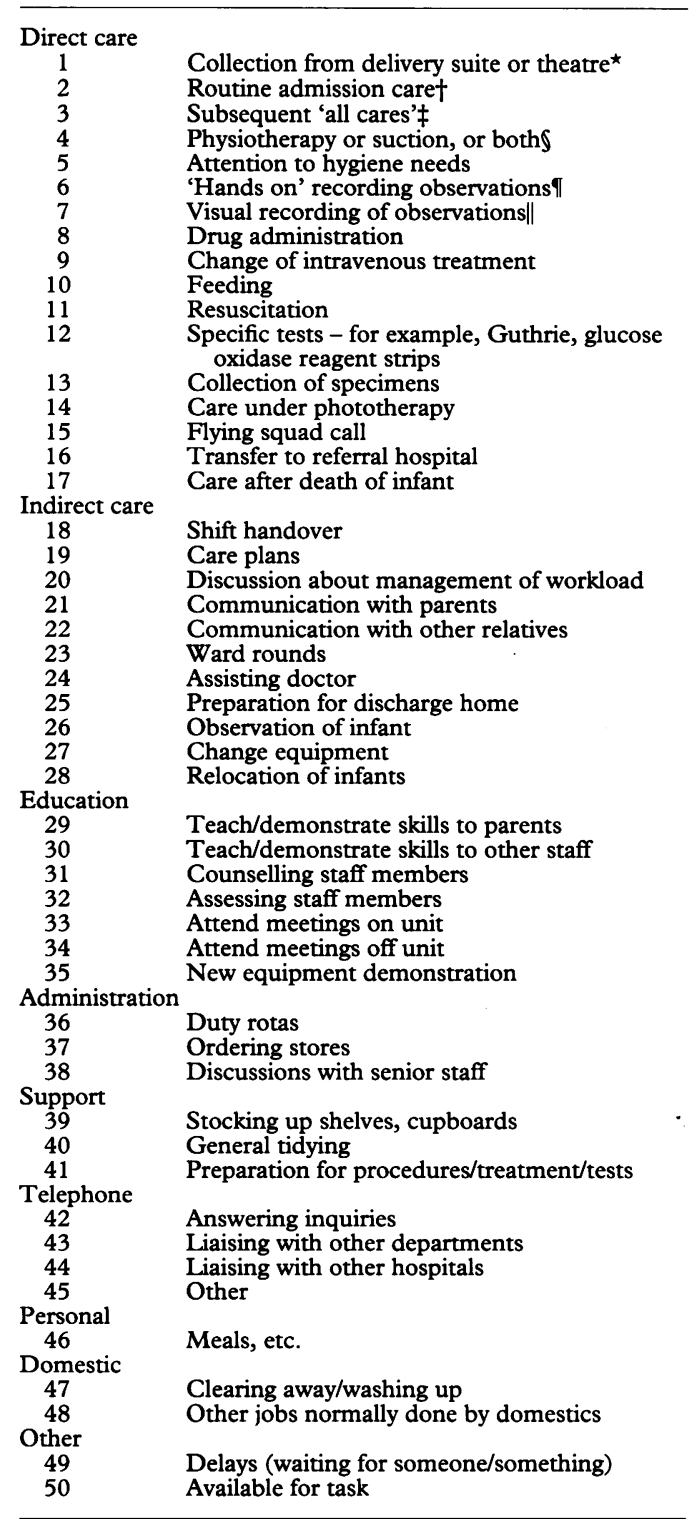

${ }^{\star}$ Collection from delivery suite/theatre: taking all specialist equipment and mobile incubator to receive/help resuscitate the infant and transfer to neonatal unit.

tRoutine admission care: this includes all care from baseline

observations on admission through the full spectrum of care to the establishment and maintenance of technical support systems.

† Subsequent 'all cares': meeting the full care needs of the infant, physical and technical - that is, weighing, washing, changing support equipment, and charts.

Physiotherapy or suction, or both, separate from 'all cares': physiotherapy and suction performed at a different time to 'all cares'.

I'Hands on' observation: nurse physically recording the infant's vital signs, checking and recording readings of technical equipment.

|Visual recording observations: observing physical appearance of infant. Checking/recording technical equipment required to of infant. Checking/recording technical

one of eight broad categories (table 1). Note was also made when there was a delay before being able to perform that task (such as waiting for someone or something) and when the nurse was available for another task. Neonatal nurses then identified each separate activity undertaken during each shift. Each of these activities was placed into one of the eight broad categories (table 1). From this it was possible to make a workcard for this study. This card, which listed all the separate activities, was then used by each participating nurse to provide an accurate record of exactly how the time spent
Table 2 Grading of nursing staff

\begin{tabular}{|c|c|}
\hline rade & Description \\
\hline A & $\begin{array}{l}\text { Nursing auxiliary used solely for cleaning equipment } \\
\text { and housekeeping duties }\end{array}$ \\
\hline B & $\begin{array}{l}\text { Nursery nurse: special care only under the direction } \\
\text { of a registered nurse }\end{array}$ \\
\hline C & $\begin{array}{l}\text { Enrolled nurse: hands on care of infants under } \\
\text { supervision }\end{array}$ \\
\hline & Registered nurse: no further qualifications \\
\hline & $\begin{array}{l}\text { Registered midwife or registered sick children's nurse } \\
\text { with varying length of experience in neonatal } \\
\text { intensive care }\end{array}$ \\
\hline $\mathbf{F}$ & $\begin{array}{l}\text { Registered nurse, registered midwife or registered sick } \\
\text { children' nurse: sister with English National Board } \\
\text { course } 405 \text { or } 904 \text { certificate and at least } 18 \text { months } \\
\text { neonatal nursing experience }\end{array}$ \\
\hline G & $\begin{array}{l}\text { Registered nurse, registered midwife or registered sick } \\
\text { children' nurse: sister with English National Board } \\
\text { course } 405 \text { or } 904 \text { certificate, experienced in } \\
\text { neonatal nursing and with some management skills }\end{array}$ \\
\hline
\end{tabular}

during a working shift had been allocated.

All grades of nursing staff (see table 2 for explanation) of varying experience participated: there were $13 \mathrm{G}$ grade nurses during the two daytime shifts and two at night, two $F$ grade nurses during day and night, $12 \mathrm{E}$ grade nurses during the day shifts and eight at night, four $\mathrm{D}$ grade nurses during the day and two at night, one $\mathrm{C}$ grade nurse during the day and three at night, and two $B$ grade nurses during the day and two at night. This phase of the study was carried out over 168 consecutive hours.

PHASE TWO: THE NURSING REQUIREMENTS OF SICK INFANTS

The purpose of this phase of the study was to identify how much nursing time was needed for each infant. Only activities associated with the nursing of that infant during a 24 hour period were recorded. This included both direct and indirect care. Account was also taken of the amount of time spent on such activities as dealing with telephone inquiries about the infant and communicating with parents. Time taken up by other activities such as administration, domestic tasks, and meal breaks were excluded. This phase took place over a four week period.

The nursing requirements of three classes of infants were studied. Fifteen infants were studied in each class. The classes were purposely kept simple so that staff should be in no doubt about the class of infant that was being looked after, and were: (a) ventilated infants; (b) those whose needs were less than (a) but more than (c), a group which is sometimes described as 'high dependency' - in practice, this included all infants who had an intravenous infusion but were not ventilated, and unstable infants who were chronically oxygen dependent; (c) 'special care' infants - that is those whose only nursing needs were help with feeding, including tube feeding, those whose parents were preparing to take them home, and those whose clinical condition was stable but who needed some additional oxygen.

PHASE THREE: TESTING THE FORMULAS

To test the results of the nursing activity analysis and the assessment of infants' nursing 
Table 3 How neonatal nurses spend their time

\begin{tabular}{|c|c|c|c|c|c|c|c|c|}
\hline \multirow[b]{2}{*}{ Activity } & \multicolumn{8}{|l|}{ Grade } \\
\hline & $B$ & $C$ & $D$ & $\begin{array}{l}E \\
\text { (day) }\end{array}$ & $\begin{array}{l}E \\
\text { (night) }\end{array}$ & $F$ & $\begin{array}{l}G \\
\text { (day) }\end{array}$ & $\begin{array}{l}G \\
\text { (night) }\end{array}$ \\
\hline Total time (minutes) & 5473 & 5877 & 5877 & 13801 & 11893 & 6989 & 14240 & 8763 \\
\hline Patient contact (\%) & $69 \cdot 3$ & $69 \cdot 0$ & $71 \cdot 2$ & $74 \cdot 8$ & $76 \cdot 2$ & $77 \cdot 2$ & $67 \cdot 8$ & $75 \cdot 4$ \\
\hline Direct care (\%) & $59 \cdot 0$ & $57 \cdot 0$ & $51 \cdot 0$ & $52 \cdot 0$ & $60 \cdot 0$ & $60 \cdot 0$ & $46 \cdot 0$ & $55 \cdot 0$ \\
\hline Indirect care $(\%)$ & $10 \cdot 0$ & $11 \cdot 7$ & $19 \cdot 8$ & $22 \cdot 5$ & $16 \cdot 4$ & $16 \cdot 8$ & $21 \cdot 4$ & $20 \cdot 1$ \\
\hline Education (\%) & 0 & $0 \cdot 7$ & 0.5 & $1 \cdot 0$ & 0 & $0 \cdot 1$ & $3 \cdot 0$ & 0.5 \\
\hline Administration (\%) & 0 & $0 \cdot 2$ & $1 \cdot 1$ & 1.9 & 0 & $0 \cdot 4$ & $2 \cdot 8$ & 0.9 \\
\hline Support $(\%)$ & $11 \cdot 7$ & 11.5 & $6 \cdot 0$ & $6 \cdot 7$ & $8 \cdot 9$ & $10 \cdot 0$ & $5 \cdot 0$ & $5 \cdot 8$ \\
\hline Telephone (\%) & $0 \cdot 8$ & $2 \cdot 8$ & $3 \cdot 5$ & $2 \cdot 5$ & $0 \cdot 7$ & 0.7 & $5 \cdot 3$ & $3 \cdot 4$ \\
\hline Personal (\%) & $9 \cdot 0$ & $10 \cdot 4$ & $11 \cdot 3$ & $10 \cdot 9$ & $8 \cdot 5$ & $7 \cdot 9$ & $10 \cdot 0$ & $9 \cdot 6$ \\
\hline Domestic (\%) & $2 \cdot 2$ & $0 \cdot 7$ & 0.4 & 0.3 & $1 \cdot 6$ & $0 \cdot 6$ & $0 \cdot 7$ & $0 \cdot 8$ \\
\hline Delays (waiting) (\%) & 0.5 & 0 & 0.7 & $0 \cdot 1$ & 0.5 & $0 \cdot 3$ & 1.8 & 0 \\
\hline Available (for task) (\%) & $6 \cdot 4$ & $4 \cdot 8$ & $5 \cdot 3$ & $1 \cdot 8$ & $3 \cdot 4$ & $2 \cdot 8$ & $3 \cdot 6$ & $3 \cdot 6$ \\
\hline
\end{tabular}

requirements, an analysis of the staffing requirements and the demands of the patients (the 'demand group') was made using the data derived in phases one and two.

We used forms which were designed at Liverpool Maternity Hospital to record the nursing requirements of each demand group (that is, ventilated infants, infants requiring high dependency care, and special care) and 'ward interventions'. This latter term was used to refer to such nursing procedures as admissions, discharges, transfers, deaths and other emergencies, and even managerial problems which took a $G$ grade nurse away from the clinical area. This ensured that all the nursing workload was taken into account for that nursing shift.

The shift leader was also asked to record the actual nursing hours spent in the ward area, with note being made of when, why, and for how long a nurse had to leave the clinical area. A note was also made of times when other nurses joined the clinical area, even temporarily.

\section{Results}

PHASE ONE: HOW NURSES SPENT THEIR TIME This part of the study showed that neonatal nurses spent between $67 \cdot 8$ and $77 \cdot 2 \%$ of their time in direct patient contact (table 3). Considering all grades of nursing staff, only $1.0 \%$ of time was spent on teaching, $1.1 \%$ on administration, $8 \cdot 1 \%$ on general support (for example, stocking shelves, generally tidying up), $2 \cdot 6 \%$ on the telephone, and $9.7 \%$ on meal breaks. The study also showed that about 45 minutes were spent listening to a handover of all the patients on the neonatal unit.

Nurses in the higher grades (E, F, and G), though appearing to have between $1 \cdot 8 \%$ and $3.6 \%$ of their time available for other activities, actually needed to be in the same room as their sick infants.

PHASE TWO: THE NURSING REQUIREMENTS OF SICK INFANTS

Over a 24 hour period the mean time accorded to each ventilated patient was 10.5 nursing hours. This comprised 3.0 hours in the morning shift ( 7.45 am to $2.00 \mathrm{pm}$ ), 3.5 hours in the afternoon shift $(2.00 \mathrm{pm}$ to $10.00 \mathrm{pm})$, and 4.0 hours during the night shift $(10.00 \mathrm{pm}$ to 7.45 am). Each high dependency patient received 9.25 nursing hours a day $(2.75$ hours in the morning, and 3.25 hours in the afternoon and during the night). Each special care patient received 6.5 nursing hours a day $(2.5$ hours in the morning, and 2.0 hours in the afternoon and during the night). There were, in addition, infants who required the undivided attention of a single nurse.

Thus the time required to look after each category of infant varied slightly according to the time of day. For example, a ventilated infant took up $48 \%$ of a nurse's shift in the morning, $44 \%$ of the afternoon shift, and $42 \%$ of the night shift.

PHASE THREE: TESTING THE DATA

Using these data we compared the expected nursing requirements of the infants on the unit for each shift with the actual numbers of nurses available to staff that shift. One hundred and twenty nine of 264 (49\%) nursing shifts were understaffed by between 1 and $27 \cdot 25$ (median $11 \cdot 25)$ nursing hours. This meant that approximately 33 extra nursing hours a day were needed, requiring $7 \cdot 5$ wte nurses.

We also compared the expected nursing time needed with the actual time that was required. Discrepancies were explained by interventions which had not been predicted. Table 4 lists the nature and the time taken to deal with these unexpected nursing activities.

Data for this comparison were completed for 166 nursing shifts. For $133(80 \%)$, there was a two hour difference or less - that is, the shift leader had predicted the workload of that

Table 4 Nursing interventions in 277 nursing shifts

\begin{tabular}{lrll} 
& & \multicolumn{2}{c}{ Duration (hours) } \\
\cline { 2 - 4 } Activity & Occasions & Median & Range \\
\hline Admissions & 131 & $2 \cdot 5$ & $0 \cdot 3-4 \cdot 0$ \\
Discharges & 44 & $0 \cdot 6$ & $0 \cdot 3-2 \cdot 5$ \\
Clerical duties & 42 & $2 \cdot 0$ & $1 \cdot 0-5 \cdot 0$ \\
Transfers & 30 & $1 \cdot 0$ & $0 \cdot 3-3 \cdot 0$ \\
Deaths & 12 & $2 \cdot 0$ & $0 \cdot 5-3 \cdot 0$ \\
Reintubation/reventilation & 6 & $0 \cdot 8$ & $0 \cdot 5-2 \cdot 5$ \\
Ventricular taps & 6 & $0 \cdot 5$ & $0 \cdot 3-2 \cdot 0$ \\
Cleaning equipment & 5 & $1 \cdot 0$ & $0 \cdot 5-2 \cdot 0$ \\
Equipment search & 3 & $1 \cdot 0$ & $1 \cdot 5-2 \cdot 0$ \\
Resuscitation & 3 & $1 \cdot 0$ & $1 \cdot 0-3 \cdot 0$ \\
Outpatient clinic & 3 & $4 \cdot 0$ & \\
Chest drain insertion & 2 & $0 \cdot 8$ & $0 \cdot 5-1 \cdot 0$ \\
Phone calls & 2 & $1 \cdot 3$ & $0 \cdot 5-2 \cdot 0$ \\
Parental support & 2 & $1 \cdot 3$ & $0 \cdot 5-2 \cdot 0$ \\
Cryosurgery & 2 & $4 \cdot 0$ & \\
Subdural tap & 1 & $0 \cdot 5$ & \\
Equipment failure & 1 & $1 \cdot 5$ & \\
Exchange transfusion & 1 & $2 \cdot 0$ & \\
& & &
\end{tabular}


shift reasonably accurately at the start of the shift and had been able to deploy her staff appropriately. For $29(17 \%)$ shifts, the nursing time required was underestimated by between 2.5 and 13.0 nursing hours (median 4.5 nursing hours), again showing understaffing on those shifts. The amount of nursing time was only overestimated by the shift leader for four shifts, and the overestimate was only between $2 \cdot 5$ and 3.0 hours.

\section{Discussion}

The differences between the amount of time needed to nurse a ventilated infant at different times of the day could be explained by the extra tasks that were performed in the morning, such as weighing the infant, supervising the radiographic procedure, and attending the doctors' round. In practice, this may mean that it might be necessary to have different numbers of nursing staff available at different times, but this would depend on the timing of daily routines which are likely to vary from hospital to hospital.

These results indicated that one nurse was able to look after two ventilated infants during one shift, and that only slightly less nursing time was needed for a high dependency infant. Between three and four special care infants could be nursed by one person.

Although our study design did not enable us to calculate precisely how long individual nursing activities took, it became clear to us in the course of this study that there were certain nursing activities which required the complete commitment of one nurse. These included: transporting an infant, regardless of whether that infant is particularly sick or being ventilated; looking after the dying baby and his or her parents; peritoneal dialysis; and assisting with an exchange transfusion.

We have also come to realise that the amount of nursing care that an infant needed was unrelated to how sick that infant was. The infant who is just starting to take sucking feeds will take longer to feed than the infant who is tube fed, and accompanying a healthy infant in an ambulance effectively removes a nurse from being available for other duties.

The descriptive categories 'intensive care', 'high dependency', and 'special care' may be helpful for describing areas in a nursery, but they do not necessarily reflect the nursing workload. The problem with these categories is that they reflect the degree of sickness of an infant rather than the amount of nursing time required by that patient. Thus, the healthy infant who is being accompanied in an ambulance by a nurse back to a local hospital takes up the same amount of nursing time as the dying infant or the sick unstable infant (who may or may not be ventilated). For the purposes of calculating nursing requirements it might be more appropriate to use four categories (A, B, C, and D), which are intended purely for the calculation of nursing time.

Category A: those tasks which completely occupy one nurse. These are, for example, admitting an infant, transport, care of the dying infant, peritoneal dialysis, and exchange transfusion. This category may include the very unstable infant who is having frequent convulsions or apnoeic episodes requiring frequent intervention.

Each of these patients needs 24 nursing hours each - that is, 5.5 wte/cot.

Category $B$ : the stable ventilated infant. Each of these patients needs 10.5 nursing hours each day - that is, 5.5 wte for 2.29 cots, or 2.4 wte/cot.

Category C: high dependency (neither category $B$ or $D)$. Each of these patients needs 9.25 nursing hours each day - that is, 5.5 wte for $2 \cdot 60$ cots, or $2 \cdot 12$ wte/cot.

Category D: special care. Each of these patients needs 6.50 nursing hours each day that is, 5.5 wte for 3.69 cots, or 1.49 wte/cot.

Owing to the unpredictable nature of neonatal intensive care, each neonatal unit will have to have an idea of its work pattern to be able to calculate how many nurses are needed. For example, as 5.5 wte nurses are required to provide 24 hour nursing cover for a single nurse on duty, a neonatal unit which undertakes the regular transport of infants will have to add 5.5 wte nurses to its establishment for that task alone.

As a consequence of this study, the work practice in our neonatal unit has changed. Now nurses only take part in the handover of the infants they will be looking after. A shift leader is appointed to each shift and she or he is the only nurse expected to have an overview of the whole ward. It was also possible to identify clerical and domestic duties which could be undertaken by persons other than trained neonatal nurses.

How do we determine how many nurses are needed for each shift? This is partly dictated by the geographical arrangement of our unit which is divided into four nurseries. For example, nurseries one and two contain about six ventilated or high dependency care infants each, and, on the basis of one nurse being needed for two infants, require an allocation of six nurses; nursery three contains four ventilated or high dependency infants, and requires two nurses; there are between six and eight special care infants in nursery four, and these require two nurses. There is also one shift leader, making a total establishment for that shift of 11 nurses. This does not take into account the need for an extra nurse to take on an additional task of, for example, transporting an infant, and, if that task can be predicted, an extra person has to be included. When calculating the numbers of nurses needed for a particular unit, nursing hours also have to be added for teaching and being taught, looking after specialist clinics, and attending meetings.

Although this activity analysis goes some way towards determining the number of nursing hours required for each shift by taking account of the demand groups and anticipated interventions, it was impossible to determine the precise skill mix required in such a specialist area because we still have not determined which grades should perform which nursing activity. Using this form of analysis we have, 
however, been able to estimate how many nursing hours were required for each shift from consideration of the type of patients currently being nursed in the nurseries. This has had two benefits. First, we were able to plan the allocation of staff more effectively. Secondly, by comparing the number of nurses available and by monitoring the hours needed we have been able to show a shortfall in the number of nurses to our chief executive and used this to support (successfully) the case of need for more neonatal nursing staff. Work patterns do, however, change, and we recognise the need to repeat this sort of study in the future.

It is important that such an analysis should be undertaken locally and by the professionals involved (rather than by an external agency) to ensure consideration of issues such as the quality of the care being provided. The interpretation of such a study should be by clinical staff and not just by managers.

1 English National Board for Nursing, Midwifery and Health Visiting. Guidelines to the staffing of neonatal units. ENB Visiting. Guidelines to

2 Royal College of Physicians of London. Medical care of the newborn in England and Wales. London: The Royal College of Physicians of London, 1988.

3 English National Board for Nursing, Midwifery and Health Visiting. Guidelines for staffing of neonatal units involved in the ENB courses. ENB Circular 1991/09/APS.

4 British Association of Perinatal Medicine. Report of working group of the British Association of Perinatal Medicine and Neonatal Nurses Association on categories of babies requiring neonatal care. Arch Dis Child 1992; 67: 868-9. 